\title{
Yeşil Tedarik Zincirinde Tam Zamanında Dağıtım Modellemesi
}

\author{
Modeling Just-in-Time distribution in a Green Supply Chain \\ Batuhan Eren ENGIN* \\ Turan PAKSOY**
}

\begin{abstract}
$\ddot{O} Z$
Son kullanıcllara malların doğru zamanda dağıtımı günümüz rekabetçi piyasasında önemli bir rol oynamaktadır. Bu bağlamda, yöneticiler, ekonomik ve çevresel hedefleri doğrultusunda uygun bir çözüm bulma gayreti içindeyken aynı zamanda, ürünlerin talep noktalarına tam zamanında teslim edilmesini ve böylece stok maliyetlerinin düşürülmesini de sağlamalıdırlar. Bu çalışma, dağıtım noktaları ve perakendecilerdeki stok tutma ile talebi doğru zamanda karşılamak arasındaki ilişkiyi ve dolayısıyla stok tutma maliyetleri ile ve karbon emisyonları arasında iliş̧kiyi araştırmayı hedeflemektedir. Bu sebeple, fabrika, depo ve perakendecilerden oluşan üç kademeli dağıtım ağı geliştirilmiş ve üç amaç fonksiyonu; toplam dağıtım ve üretim maliyeti, depolarda ve perakendecilerde ürünlerin depolanması ve elleçlenmesiyle ilişkili toplam karbon emisyonu ve perakendecilerden ardısmarlanmış (karşılanamamış, sonraya ertelenen, ingilizce: backordered) ürünlerin ve talep fazlası ürünlerin saylsı olarak belirlenmiştir. Gelişstirilen model, hangi üreticiden, depolara ve oradan perakendecilere, perakendecilerin talebine cevap vermek için ne kadar miktarlarda taşınacağını, hangi fabrika ve depoların hangi boyutlarda açılacağını, depolardaki envanter miktarlarını da belirlemektedir. Bu çok amaçlı tam zamanında dağıtım modellemesi içeren yeşil tedarik zinciri modelinin çözümü için Tiwari, Dharmar ve Rao (1987) tarafindan geliştirilen bulanık ağırlıklandırma yaklaşımı ilk defa kulanılmıştır. Pratik açıdan, çelişsen ve farklı birimlere sahip amaçların aynı anda optimize edilmesine olanak verdiği için bu yöntem, yöneticiler ve karar vericiler açısından önem tașımaktadır. Bu bulanık edinim yöntemi, yöneticilerin her bir hedef ișlev için göreli önemlerini belirlermesine imkan sağlaması da ayrıca önemlidir, çünkü bu sayede yöneticiler, hedeflerin de birbirlerine göre önem derecelerini kendi tedarik zincirlerine göre belirleyebilirler.
\end{abstract}

\section{ANAHTAR KELIMELER \\ Çok Amaçlı Optimizasyon, Yeşil Tedarik Zinciri, Tam Zamanında Dağıtım}

\begin{abstract}
The right-on-time distribution of goods to the end-users plays an important role in nowadays competitive market. Companies intend to find the balance between organizational cost and environmental footprint, which is a challenging practice, as these objectives are usually conflicting. In this context, from a practical point, managers are willing to find a good compromise solution to both satisfy economic and environmental goals while they need to make sure that the products are delivered right-on-time to the demand point, thereby reducing inventory costs. This study aims to research the inter-relationship between holding inventory at warehouses and retailers to satisfy the demand right-on-time, and its impact on costs and carbon emissions. Three echelon distribution network consisting of manufacturers, warehouses and retailers is developed and three objectives; i.e., total distribution and manufacturing cost, total carbon emission associated with storing and handling of goods at warehouses and retailers, and the sum of backordered goods from retailers and surpluses of goods at retailers, are considered. The developed model decides the quantity of products transported from factories to warehouses and from there, to retailers to satisfy the demand realized at retailers. The model also decides the sizes of factories and warehouses to be opened. To solve this multi-objective, green supply chain involving Just-in-time distribution, we applied fuzzy weighted additive model developed by Tiwari ve diğ. (1987). From a practical point of view, this method offers a great tool for managers and practitioners as it optimizes multiple objectives simultaneously. This method allows the managers to adjust the relative importance ratios for each objective function, which also helps the managers to truly manage the network performance measures.
\end{abstract}

\section{KEYWORDS}

Multi-Objective Optimization; Green Supply Chain; Just-In-Time Distribution

\begin{tabular}{|c|c|c|}
\hline \multicolumn{2}{|c|}{ Makale Geliş Tarihi / Submission Date } & \multicolumn{1}{c|}{$\begin{array}{c}\text { Makale Kabul Tarihi / Date of Acceptance } \\
\text { 30.10.2018.2019 }\end{array}$} \\
\hline \multirow{3}{*}{ Atıf } & $\begin{array}{l}\text { Engin, B.E., Paksoy, T. (2019). Yeşil Tedarik Zincirinde Tam Zamanında Dağıtım Modellemesi. Selçuk Üniversitesi } \\
\text { Sosyal Bilimler Meslek Yüksekokulu Dergisi, 22 (1), 93-103 }\end{array}$ \\
\hline
\end{tabular}

\footnotetext{
*Arş. Gör., Konya Teknik Üniversitesi, Mühendislik ve Doğa Bil. Fakültesi, Endüstri Müh., erengn@ gmail.com, ORCID: 0000-0002-3898-0855

** Profesör, Konya Teknik Üniversitesi, Mühendislik ve Doğa Bil. Fakültesi, Endüstri Müh., tpaksoy@ yahoo.com, ORCID: 0000-0001-8051-8560
} 


\section{GİRIŞ}

Günümüz rekabetçi piyasasında ürünlerin tam zamanında talep noktasında olmaları oldukça önem kazanmıştır. Müşterilerin taleplerini zamanında karşılayabilmek, maliyetlerde düşüşlere yol açacak ve aynı zamanda tedarik zincirinin hizmet seviyesini de artıracaktır. Küresel pazarların rekabetçi ortamı, birçok üreticiyi toplam maliyetlerin ve boşa harcanan zamanın azaltılması için en uygun tedarik zinciri tasarımını seçmeye zorlamaktadır.

Ancak şirketler bir yandan da, üretimden ve dağıtımdan kaynaklanan çevresel ayak izini bu amaca yönelik çıkarılmış uluslararası mevzuat ve yönetmelikler sebebiyle azaltmak durumundadırlar. Bu nedenle şirketler, genellikle çelişen operasyonel maliyet ve çevresel ayak izi arasındaki dengeyi bulmayı amaçlamaktadırlar.

Tam zamanında dağıtım (TZD, ing. Just-in-time (JIT)), malların verimli dağıtımında önemli rol oynamaktadır. Bir perakendeci ürün siparişleri verdiğinde maliyet ve teslimat konularında önem verir. Envanter kontrolü ve dağıtım planlaması, temel lojistik süreçler olarak tedarik zincirinin toplam maliyetini büyük ölçüde etkilemekle birlikte, diğer taraftan, müşterilerin hizmet seviyesi üzerinde büyük bir etkiye sahiptir. JIT politikasına göre, her tedarikçinin doğru zamanda ve doğru zamanda doğru miktarda mal teslim etmesi gerekmektedir. Tam zamanında teslimat kavramı genel olarak modellere erken/geç teslimata dair açığa çıkan ceza maliyetleri ile dahil edilir, ancak burada maliyetin en aza indirilmesi ile çelişen yeni bir amaç fonksiyonu olarak tanımlanmıştır. Ortaya çıkan çok amaçlı karışık tamsayı doğrusal programlamanın gerçek boyuttaki problemleri kesin yöntemler kullanılarak çözülemez, ancak bunun için çok-amaçlı optimizasyon metodları kullanılabilir. Bu çalışmada, Tiwari ve diğ. (1987) tarafından geliştirilen bulanık ağırlıklandırma yaklaşımı kullanılmıştır. Bu yöntem, her bir amaca yönelik ağırlık atama imkanı da sunması, farklı amaçların farklı ağırlıklara sahip olduğu tedarik zinciri yönetiminde önemli olabilir.

Literatürde tam zamanında dağıtım modellemesini içeren benzer çalışmalar bulunmaktadır (Farahani \& Elahipanah, 2008; Ghasimi, Ramli, \& Saibani, 2014; S. Wang \& Sarker, 2006; W. Wang, Fung, \& Chai, 2004; Zimmer, 2002). Örneğin, Farahani ve Elahipanah (2008), tedarik zinciri yönetimi kapsamında tam zamanında dağıtımını modellemişlerdir. İki aşamalı bir tedarik zincirinde maliyetlerin en aza indirilmesi ve her dönemdeki ardısmarlanmış ve talep fazlası ürünlerin toplamının minimize edilmesi olmak üzere iki-amaç fonksiyonuna sahip bir model oluşturmuşlardır. Tam zamanlı dağıtım kuramını ise her dönemdeki ardısmarlanmış ve talep fazlası ürünlerin toplamının (miktar) minimize edilmesi olarak ele almışlardır. Karma-tamsayı doğrusal programlama modelinin gerçek boyut problemlerini çözmek için ise Non-dominant Sorting Genetic algorithmII (NSGA-II) adlı, çok-amaçlı optimizasyon modellerinin çözümünde kullanılan güçlü bir genetik algoritma geliştirmişlerdir. Ghasimi ve diğ. (2014) amacın, üretim, dağıtım, tutma ve geri ödeme maliyetlerini en aza indirmek olduğu bir kusurlu mal tedarik zinciri ağı tasarlamışlardır. Önerilen modelde, tüm kusurlu kaliteli ürünlerin tamir edilemez olduğunu, ancak hurda olarak değerlendirilenlerin doğrudan müşterilere düşük fiyatla satıldığını varsaymışlardır. Maliyetlerin en aza indirilmesine ek olarak, model, ekonomik üretim miktarını (EPQ), her döngünün uygun uzunluğunu tam zamanında dağıtım düşüncesiyle belirlemektedir. Gerçek yaşam koşullarında incelenen modelin geçerliliği için olasılık parametrelerine ve çeşitli boyutlara sahip genetik algoritma (GA) geliştirmişlerdir. S. Wang ve Sarker (2006), çok aşamalı bir tedarik zinciri sistemine TZD politikası uygulamıştır. Modelde TZD felsefesini uygulayabilmek için kullandıkları Kanbanlar, tedarik zinciri sistemindeki bilgi ve malzeme akışlarında önemli bir rol oynamaktadır. Bi karma tamsayılı doğrusal olmayan programlama modeli olarak ele aldıkları problemde, Kanban kartlarını bir kamyon veya foklift olarak yansıtmışlardır. Kanban sayısı, parti büyüklüğü, parti sayısı ve bir periyottaki toplam miktarı optimize etmeyi hedeflemişlerdir. W. Wang ve diğ . (2004) çoklu depo ve çok perakendecili ve tam zamanında dağıtım felsefesini içeren bir tedarik zinciri modeli geliştirmişlerdir. Modeldeki üretim ve taşımacıllı̆ı̆ı toplam maliyetini minimize etmenin yanında, tam zamanında dağıtım felsefesinin getirdiği, perakendecilere yapılan erken veya geç teslimatlardan kaynaklana bir ceza maliyetini de amaç fonksiyonunda hesaba katmışlardır. Ancak bu çalışmaların hiçbirinde tasarlanan tedarik zinciri, aynı zamanda karbon salınımını da minimize etme gayreti içinde olmamıştır. Ayrıca, Tiwari ve diğ. (1987) tarafından geliştirilen bulanık ağılıklandırma yaklaşımı da, tam zamanında dağıtım modellemesi içeren yeşil bir tedarik zincirinde ilk defa kullanılmıştır.

Çok amaçlı optimizasyon problemleri ise literatürde giderek yaygınlaşmaya başlamıştır. Çözüm yöntemleri konusunda ise farklı çözüm yöntemleri mevcuttur, $\epsilon$-kısıtlama yöntemini bunlardan birisidir (Banasik, Kanellopoulos, Claassen, Bloemhof-Ruwaard, \& van der Vorst, 2017; Soleimani, Govindan, Saghafi, \& Jafari, 2017; Talaei, Farhang Moghaddam, Pishvaee, Bozorgi-Amiri, \& Gholamnejad, 2016). Örneğin, Soleimani ve diğ. (2017) toplam kârın maksimize edilmesi, yeni ve geri dönüştürülmüş ürünlere yönelik müşteri taleplerinin karşılanması, ve iş tehlikeleri ve kazalar nedeniyle kaçırılan iş günlerinin en aza indirilmesi için çok amaçlı, yeşil kapalı döngü bir tedarik zinciri tasarlamış ve $\epsilon$-kısıtlama yöntemini kullanmışlardır. Çok amaçlı 
problemler, tek bir cins üzerinden ifade edilebilirse, çok amaçlı fonksiyon tek amaca indirilebilir, örneğin, Fahimnia, Sarkis ve Eshragh (2015), karbon emisyonları, enerji tüketimi ve atı üretimi de dahil olmak üzere, maliyet ve çevresel bozulma arasındaki ilişkiyi ele alan bir tedarik zinciri modeli için karma-tamsayılı doğrusal olmayan matematiksel model önermişlerdir. Önerilen matematiksel modelin tüm amaçları, eşdeğer dolar cinsinden ifade edilerek, çok amaçlı model tek bir ağırlıklı toplam amaçlı optimizasyon problemine çevrilerek çözümü gerçekleştirilmiştir. Çok amaçlı optimizasyon problemleri için özel olarak geliştirilmiş evrimsel algoritma türevleri de ayrica bulunmaktadır (Chan, Jha, \& Tiwari, 2016; Sadeghi Rad \& Nahavandi, 2018). Tiwari ve diğ. (1987) tarafından geliştirilen bulanık ağırlıklı çözüm yaklaşımı ise daha çok tedarikçi seçim problemi için kullanılmıştır (Amid, Ghodsypour, \& O'Brien, 2009; Arikan, 2013; Kavitha, 2013; Mehlawat \& Kumar, 2017; Pan, Wang, Guo, \& Liu, 2015; Seifbarghy, Pourebrahim Gilkalayeh, \& Alidoost, 2011; Shaw, Shankar, Yadav, \& Thakur, 2012). Bu çalışmanın literatüre katkısı ise, bu metodun ilk defa tam zamanında dağıtım modellemesi içeren yeşil bir tedarik zincirinde kullanılması olacaktır. Bu bağlamda, bu çalışma, bulanık ağırlıklı edinim yöntemi kullanarak ekonomik, çevresel ve TZD bağlantılı erken/geç teslim edilen ürün sayısını azaltmak gibi farklı ve çelişen amaçları aynı anda iyileştirmek isteyen yöneticiler için bir örnek oluşturmaktır.

\section{YEŞİL TEDARIK ZİNCIRIINDE TAM ZAMANLI DAĞITIM MODELLEMESİ}

Bu çalışmada, fabrika, depo ve perakendeciyi içeren 3-aşamalı yeşil bir tedarik zinciri tasarlanmıştır ve 2 dügüm arasında her periyottaki optimal taşıma miktarlarını bulmayı amaçlayan bir matematiksel model oluşturulmuştur. Yaptığımız literatür taraması göstermiştir ki, tam zamanında dağıtım felsefesi, henüz yeşil bir tedarik zinciri ağında uygulanmamıştır. Bu çalışmada üretim, depolama, taşıma maliyetinin en küçüklenmesinin yanında, tedarik zincirindeki toplam karbon emisyonu ve ayrıca perakendecilerde, her bir dönemdeki talep fazlası ürünlerin ve ardısmarlanmış ürünlerin sayısının da en küçüklenmesi amaçlanmıştır. Fabrikaların açılacak büyüklügüne göre değişen üretim kapasiteleri, depoların büyüklüklerine göre değişen depolama kapasiteleri ve perakendecilerin de depo kapasiteleri mevcuttur. Başlangıçta ve planlama ufkunun sonunda depolarda stok bulunmamaktadır ve planlama ufku sonuna kadar tüm taleplerin er ya da geç tatmin edilmesi gerekmektedir. Perakendecilere gelen talepler belirlidir.

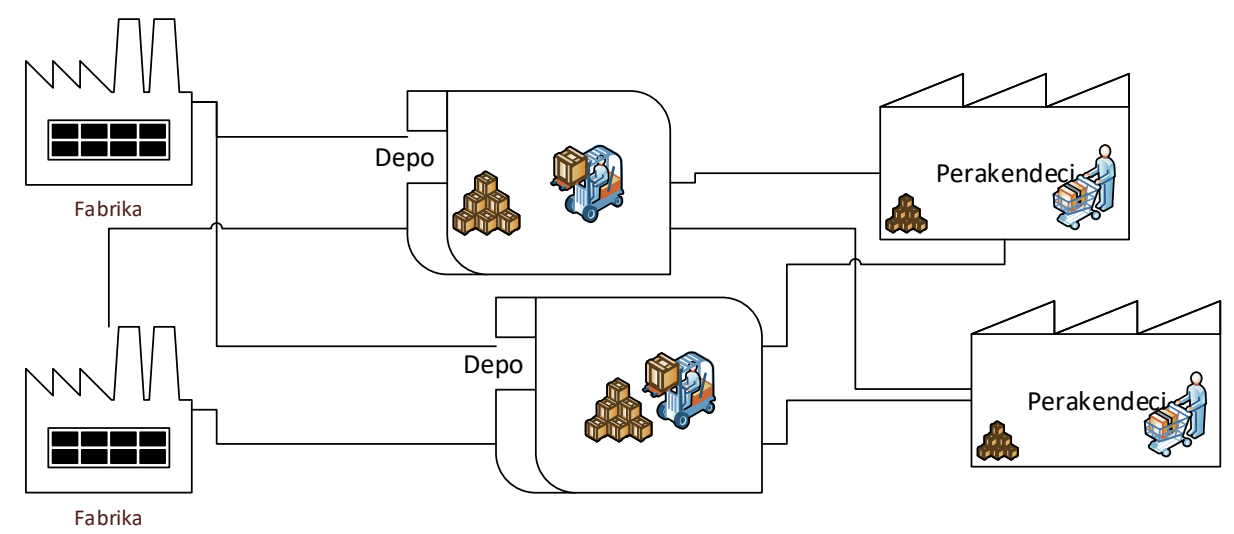

Figür 1.Tedarik zinciri şeması

Önerilen modelin geliştirilmesinde aşağıdaki varsayımlar kullanılmıştır:

1. Perakendecilerin talepleri, planlama öncesinde bilinmektedir.

2. Perakendecilerde, talebin karşılanmadığı noktada talep ardısmarlanır.

3. Çoklu-dönem olarak tasarlanan model, birden fazla fabrika, depo, perakendecilerden oluşmaktadır.

4. Tesislerin, dağıtıcıların, perakendecilerin ve tedarikçilerin yerleri sabittir.

5. Üreticilerin, depoların ve perakendecilerin kapasiteleri bilinmektedir ve sınırlıdır.

6. Ürünler perakendecilere teslim edilmeden önce distribütörlerde saklanabilir.

7. Planlama ufkunun başında veya sonunda dağıtıcılarda envanter bulunmamaktadır.

8. Planlama ufku sonunda perakendecilerin tüm talepleri karşılanmalıdır. 
9. İlk ve son periyotta depolardaki ve perakendecideki envanter miktarları ile, perakendecilerde ardısmarlanmış ürün miktarı 0'a eşittir.

Bu modelde kullanılan kümeler ve indeksler aşağıdaki gibidir:

I Fabrika kümesi, i ile endeksli

W Depo kümesi, w ile endeksli

J Perakendeci kümesi, j ile endeksli

$\mathrm{T}$ Zaman periyodu kümesi, t ile endeksli

K Fabrika-depo boyut kümesi, k ile endeksli

\section{Değişkenler:}

$X_{i w t}^{k}$ : $k$ büyüklügündeki $i$ fabrikasından $w$ deposuna $t$ zamanında gönderilen ürün miktarı

$Y_{w j t}^{k}: k$ büyüklüğündeki $w$ deposundan j perakendecisine $t$ zamanında gönderilen ürün miktarı

$O_{i k}: k$ büyüklüğündeki $i$ fabrikasının açılıp açılmadığını belirten ikili değişken

$O^{\prime}{ }_{w k} \quad: k$ büyüklüğündeki $w$ deposunun açılıp açılmadığını belirten ikili değişken

$B_{j t}: j$ perakendecisinden ardısmarlanmış

$S_{j t} \quad: j$ perakendecisinde $t$ dönemindeki talep fazlas 1

$V_{j t}: j$ perakendecisinde $t$ dönemindeki talep fazlası veya ardısmarlanmış ürün durumunu gösteren ikili değişken

\section{Parametreler:}

$Q m_{i t}^{k} \quad$ :k büyüklüğündeki i fabrikasının t dönemindeki üretim kapasitesi

$Q_{w t}^{k}: \mathrm{k}$ büyüklügündeki w deposunun t dönemindeki depolama kapasitesi

$Q^{\prime}{ }_{j t}$ :j perakendecisinin t dönemindeki depolama kapasitesi

$c a_{w t}^{k} \quad: k$ büyüklügündeki w deposunun t dönemindeki elleçleme kapasitesi

$c a^{\prime}{ }_{j t}$ :j perakendecisinin t dönemindeki elleçleme kapasitesi

$f i x_{i k} \quad$ :i fabrikasını k büyüklügünde kurma maliyeti

$f i x_{w k} \quad:$ w deposunu k büyüklügünde kurma maliyeti

$d_{j t}:$ j perakendecisinin t dönemindeki talebi

dis $\quad$ :i fabrikası ile w deposu arasındaki mesafe

$d i s^{\prime}{ }_{w j} \quad$ :w deposu ile j perakendecisi arasındaki mesafe

$h_{w k t} \quad$ :k büyüklüğündeki w deposunun $\mathrm{t}$ dönemindeki ürün başına depolama maliyeti

$h_{j t}^{\prime}$ :j perakendecisinde t dönemindeki ürün başına depolama maliyeti

$c \quad$ :birim taşıma maliyeti

$\operatorname{prod}_{i k} \quad: \mathrm{k}$ büyüklüğündeki i fabrikasında birim üretim maliyeti

$c e_{i k t}^{p} \quad: k$ büyüklügündeki i fabrikasında t döneminde birim üretim karbon emisyon miktarı

$c e_{i k t}^{\max } \quad: \mathrm{k}$ büyüklüğ̈ndeki i fabrikasında $\mathrm{t}$ döneminde izin verilen maksimum toplam karbon emisyon miktarı

$b l_{j t}$ :j perakendecisindeki t döneminde izin verilen maksimum ardısmarlanmış ürün miktarı

$c_{w k t}^{\text {hold }} \quad: \mathrm{k}$ büyüklüğündeki i fabrikasında t döneminde birim depolama karbon emisyon miktarı

$c_{w k t}^{\max } \quad: \mathrm{k}$ büyüklüğündeki i fabrikasında $\mathrm{t}$ döneminde izin verilen toplam maksimum karbon emisyon miktarı

$\mathrm{cr}_{j t}^{\text {hold }} \quad$ :j perakendecisi t döneminde birim depolama karbon emisyon miktarı

$\mathrm{cr}_{j t}^{\max } \quad$ :j perakendecisi t döneminde izin verilen toplam maksimum karbon emisyon miktarı

$c_{w k t}^{\text {hand }} \quad$ :k büyüklügündeki w deposunun t dönemindeki ürün başına elleçleme karbon emisyon

miktarı

$\operatorname{cr}_{j t}^{\text {hand }} \quad:$ j perakendecisinde t dönemindeki ürün başına elleçleme karbon emisyon miktarı 


\section{Amaç fonksiyonları:}

$$
\begin{gathered}
\operatorname{Min} Z_{1}=\sum_{i, w, t, k} X_{i w t}^{k} *\left(c * d i s_{i w}+\operatorname{prod}_{i k}\right)+\sum_{i, k} f i x_{i k} O_{i k}+\sum_{w, j, t, k} Y_{w j t}^{k} * c * d i s_{w j} \\
+\sum_{w, k} f i x_{w k} O^{\prime}{ }_{w k}+\sum_{t=1}^{T-1} \sum_{w, k} h_{w k t}\left(I Q_{w k t}\right)+\sum_{j, t} h_{j t}^{\prime} * S_{j t} \\
\operatorname{Min} Z_{2}=\sum_{j, t} B_{j t}+S_{j t} \\
\operatorname{Min} Z_{3}=\sum_{i, k, t}\left(c e_{i k t}^{p} * \sum_{w} X_{i w t}^{k}\right)+\sum_{t=1}^{T-1} \sum_{w, k} c_{w k t}^{\text {hold }}\left(I Q_{w k t}\right)+\sum_{j, t} c r_{j t}^{\text {hold }} * S_{j t} \\
+\sum_{j, t}\left(c r_{j t}^{\text {hand }} * \sum_{w, k} Y_{w j t}^{k}\right)+\sum_{w, k, t}\left(c_{w k t}^{h a n d} * \sum_{i} X_{i w t}^{k}\right)
\end{gathered}
$$

Kisitlar:

$$
\begin{aligned}
& \sum_{w} X_{i w t}^{k} \leq Q m_{i t}^{k} * O_{i k}, \quad \forall k, i, t \\
& \sum_{k} O_{i k} \leq 1 ; \quad \forall i \\
& \sum_{k} O^{\prime}{ }_{w k} \leq 1 ; \quad \forall w \\
& \sum_{w, k, j} Y_{w j t}^{k}=\sum_{t} d_{j t} \quad \forall j \\
& \sum_{i, k, t} X_{i w t}^{k}=\sum_{k, j, t} Y_{w j t}^{k} \quad \forall w \\
& \sum_{i} X_{i w t}^{k} \leq c a_{w t}^{k} * O^{\prime}{ }_{w k} \quad \forall w, t, k \\
& \sum_{\tau=1}^{t} \sum_{i} X_{i w t}^{k}-\sum_{\tau=1}^{t} \sum_{j} Y_{w j t}^{k}=I Q_{w k t} \quad \forall w, k, t \\
& I Q_{w k t} \leq Q_{w t}^{k} \quad \forall w, k, t \\
& \sum_{i, k} \sum_{\tau=1}^{t} X_{i w t}^{k} \geq \sum_{k, j} \sum_{\tau=1}^{t} Y_{w j t}^{k} \quad \forall w, t \\
& \sum_{\tau=1}^{t} \sum_{w, k} Y_{w j t}^{k}-\sum_{\tau=1}^{t} d_{j t}=S_{j t}-B_{j t} \quad \forall j, t \\
& \sum_{w, k} Y_{w j t}^{k} \leq c a_{j t}^{\prime} \quad \forall j, t \\
& S_{j t} \leq V_{j t} * Q_{j t}^{\prime} \quad \forall j, t \\
& B_{j t} \leq\left(1-V_{j t}\right) * b l_{j t} \quad \forall j, t \\
& c e_{i k t}^{p} * \sum_{w} X_{i w t}^{k} \leq c e_{i k t}^{\max } \quad \forall k, i, t \\
& c_{w k t}^{\text {hold }} *\left(I Q_{w k t}\right)+\sum_{i} X_{i w t}^{k} * c_{w k t}^{\text {hand }} \leq c_{w k t}^{\max } \quad \forall w, k, t \\
& c r_{j t}^{\text {hold }} * S_{j t}+\sum_{w, k} Y_{w j t}^{k} * c r_{j t}^{\text {hand }} \leq c r_{j t}^{\max } \quad \forall j, t \\
& X_{i w t}^{k}, Y_{w j t}^{k}, S_{j t}, B_{j t} \geq 0, \quad \forall i, w, k, j, t \\
& O_{i k}, O^{\prime}{ }_{w k}, V_{j t} \in\{0,1\}, \quad \forall i, w, k, j, t
\end{aligned}
$$




\section{Çözüm metodu: Bulanık Ağırlıklandırma Yöntemi}

Tiwari ve di ̆. (1987) tarafından geliştirilen bulanık ağırlıklandırma yaklaşımı, çok amaçlı optimizasyon fonksiyonuna sahip modelleri çözmek için geliştirilmiş bir yöntemdir. Bu metod, çok amaçlı amaç fonksiyonunu, her bir fonksiyon için hesaplanan bir üyelik fonksiyonu kullanarak, tek amaca indirger. Ağırlıklar $\left(\rho_{1}, \rho_{2}, \rho_{3}\right)$ karar verici tarafindan üç amaç fonksiyonunun ağırlığını yansıtacak şekilde atanır. Bir maksimizasyon problemi için temel ağırlıklı modeli şu şekilde kurulur:

$$
\operatorname{Maks} V(\mu)=\sum_{i=1}^{m} \rho_{i} \mu_{i}
$$

Kisitlar:

$$
\begin{gathered}
\mu_{i}=\frac{G_{i}(X)-L_{i}}{g_{i}-L_{i}} \\
A X \leq b \\
\mu_{i} \leq 1 \\
X, \mu_{i} \geq 0, \quad i=1,2, \ldots, m
\end{gathered}
$$

$\mathrm{X} x_{1}, x_{2}, \ldots, x_{n}{ }^{\prime}$ lerden oluşan bir $\mathrm{n}$ boyutlu vektör ve $A X \leq b$ ise vektör formatında modelin kısıtlarıdır. Zimmermann (1978)'a göre doğrusal üyelik fonksiyonu, $\mu_{i}$ i. bulanık amaç için, $G_{i}(X) \geq g_{i}$, şu şekilde tanımlanabilir:

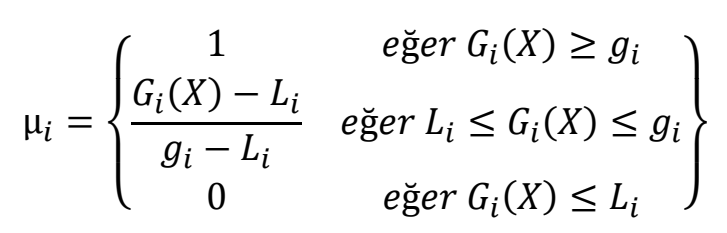

Burada $L_{i}$, bulanık amaç $G_{i}(X)$ için alt sınırdır. Amacın $G_{i}(X) \leq g_{i}$ şeklinde olması durumunda ise üyelik fonksiyonu aşağıdaki gibi tanımlanabilir:

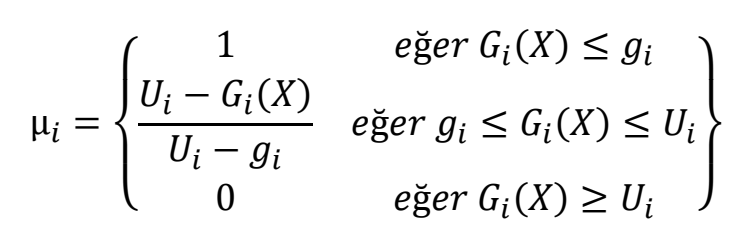

Burada $U_{i}$ ise, üst tolerans limitidir. Amaç fonksiyonunda ise $V(\mu)$ terimi, bulanık edinim fonksiyonudur. $\mathrm{Bu}$, temel optimizasyon teknikleriyle çözülebilen tek amaçlı bir optimizasyon problemidir.

\section{Örnek Vaka Analizi}

Bu bölümde, geliştirilen matematiksel model ve çözüm yöntemi sayısal bir örnek ile denenmiştir. Geliştirilen tedarik ağında, açılacak fabrikalar, depoların yerlerine ve büyüklüklerine karar verilmek istenmektedir. Vaka analizine dair parametre bilgileri şu şekilde verilmiştir: 
Tablo 1 Örnek probleme dair parametreler

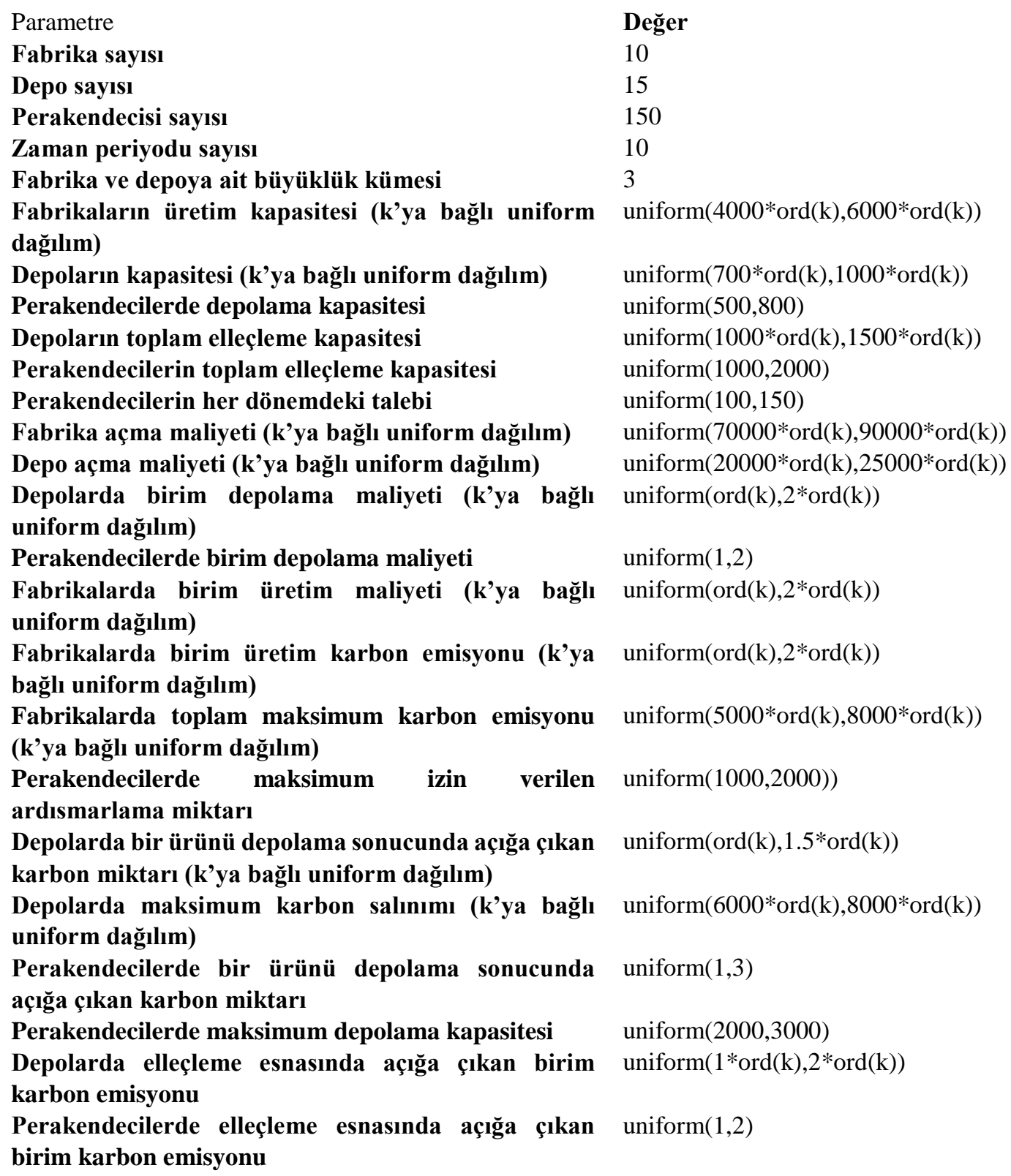

Üç farklı birime sahip amaç fonksiyonu; toplam üretim, taşıma ve depolama maliyeti $\left(Z_{1}\right)$, perakendecilerden ardısmarlanmış ve talep fazlası ürünlerin sayısı $\left(Z_{2}\right)$ ve depolarda ve perakendecilerde ürünlerin depolanması ve elleçlenmesiyle ilişkin toplam karbon emisyonu $\left(Z_{3}\right)$ olarak belirlenmiştir.

Tablo 2. Üç amaç fonksiyonu için ikili karşılaştırma matrisi

$\begin{array}{cccc}\text { Amaç Fonksiyonu } & \mathbf{Z}_{\mathbf{1}} & \mathbf{Z}_{\mathbf{2}} & \mathbf{Z}_{\mathbf{3}} \\ \mathbf{Z}_{\mathbf{1}} & 1 & 5 & 3 \\ \mathbf{Z}_{\mathbf{2}} & 1 / 5 & 1 & 1 / 3 \\ \mathbf{Z}_{\mathbf{3}} & 1 / 3 & 3 & 1\end{array}$

Tablo 2'de verilen 1'den 9'a kadar olan ölçek kullanılarak, üç objektif fonksiyonun ikili olarak karşılaştırılmasını gerçekleştirilmiş ve bundan sonra çok amaçlı bir teknik olan ve Saaty (2008) tarafindan geliştirilen Analitik Hiyerarşi prosesi, her bir amaç fonksiyonu için ağırlıkların elde edilmesinde kullanılmıştır.. Tablo 1'den, toplam maliyetin $\left(Z_{1}\right)$, toplam karbon emisyonundan $\left(Z_{3}\right)$ biraz daha önemli 
olduğu, toplam talep fazlası ve ardısmarlamış ürün miktarları toplamından daha önemli olduğu $\left(Z_{2}\right)$ okunabilir. AHP ve uygulaması hakkında daha fazla bilgi Saaty (2008) çalışmasında bulunabilir.

Tutarlı değerlendirmeye sahip ikili karşılaştırma matrisi sayesinde, ağırlık vektörü [0.633 0.1060 .259$]^{T}$ olarak bulunmuştur. Bu ağırlıklar, bulanık doğrusal programlamanın her bir üyelik fonksiyonu ile çarpılır. Bir sonraki adım, üyelik fonksiyonlarını, yani $\mu_{i}$ değişkenlerini hesaplamaktır. Üyelik fonksiyonlarını hesaplamak için ilk adım, bir seferde tek bir hedefi optimize edecek şekilde modeli, her bir amaç fonksiyonu adedince çalıştırmaktır. İlk hedefi $\left(Z_{1}\right)$ çözdükten sonra, ilk hedefin alt sınır optimal değeri, hedef alınan amaç fonksiyonunun maksimizasyonu ve minimizasyonu şeklinde elde edilir. Süreç kalan iki hedef için birer birer tekrarlanır. Her bir hedef için alt sınır ve üst sınır aynı kısıtlar kümesi kullanılarak hesaplanır. Bulanık formülasyon Tiwari ve diğ. (1987) tarafından geliştirilen tarafından önerilen ağırlıklı edinim modeli kullanılarak yapılır. Tablo 3, her bir amaç için bulunan üst ve alt sınırları içermektedir.

Tablo 3. Üst ve alt sınırlar

$\begin{array}{cll}\text { Amaç Fonk. } & \text { Maks } & \text { Min } \\ \mathbf{Z}_{\mathbf{1}} & 17183933 & 6231020 \\ \mathbf{Z}_{\mathbf{2}} & 738361 & 0 \\ \mathbf{Z}_{\mathbf{3}} & 4344971 & 1152965\end{array}$

Amaç fonksiyonlarını aldıkları en küçük ve en büyük değerler de Tablo 4'de verilmiştir.

Tablo 4. Amaç fonksiyonlarını minimum ve maksimum değerleri

$\begin{array}{lcll}\text { Obj. No } & \text { Amaçfonksiyonu } & \mu=1 & \mu=0 \\ 1 & Z_{1} & 6231020 & 17183933 \\ 2 & Z_{2} & 0 & 738361 \\ 3 & Z_{3} & 1152965 & 4344971\end{array}$

Üyelik işlevlerinin doğrusal olduğunu varsayarak, üyelik fonksiyonları şu şekilde hesaplanır:

$$
\begin{aligned}
& \mu_{1}=\left\{\begin{array}{cc}
1 & \text { ĕ } \text { er } Z_{1} \leq 6231020 \\
\frac{17183933-Z_{1}}{17183933-6231020} & \text { ĕger } 6231020 \leq Z_{1} \leq 17183933 \\
0 & \text { ĕ } \text { er } Z_{1} \geq 17183933
\end{array}\right\} \\
& \mu_{2}=\left\{\begin{array}{cc}
1 & \text { ĕger } Z_{2} \leq 0 \\
\frac{738361-Z_{2}}{738361} & \text { ĕ } \text { er } 0 \leq Z_{2} \leq 738361 \\
0 & \text { ĕger } Z_{2} \geq 738361
\end{array}\right\}
\end{aligned}
$$

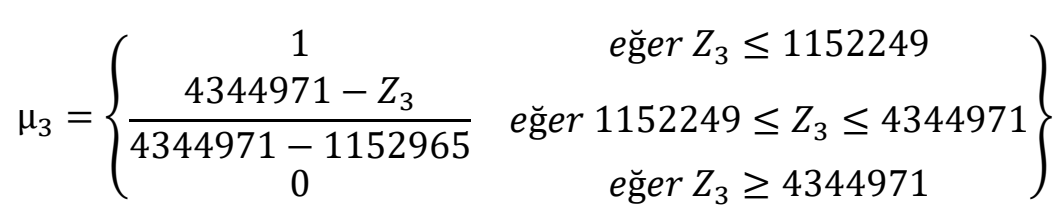

Bu üyelik fonksiyonlarını kullanarak, TZD uygulamalı yeşil tedarik zinciri problemi için yeni matematiksel formülasyon aşağıdaki gibidir: 


$$
\text { Maks } Z=0.633 * \mu_{1}+0.106 * \mu_{2}+0.259 * \mu_{3}
$$

\section{Kisitlar:}

$$
\begin{gathered}
\mu_{1} \leq \frac{17183933-Z_{1}}{17183933-6231020} \\
\mu_{2} \leq \frac{738361-Z_{2}}{738361} \\
\mu_{3} \leq \frac{4344971-Z_{3}}{4344971-1152965}
\end{gathered}
$$

Yukarıda detaylandırılan matematiksel model, C \# dilinde Visual Studio ortamında ILOG'in CPLEX Concert Technology (sürüm 12.6) kullanılarak gerçekleştirilmiştir. Bulanık matematiksel modelin optimal çözümü aşağıdaki Tablo 5 'te verilmiştir.

\section{Tablo 5. Optimal Çözüm}
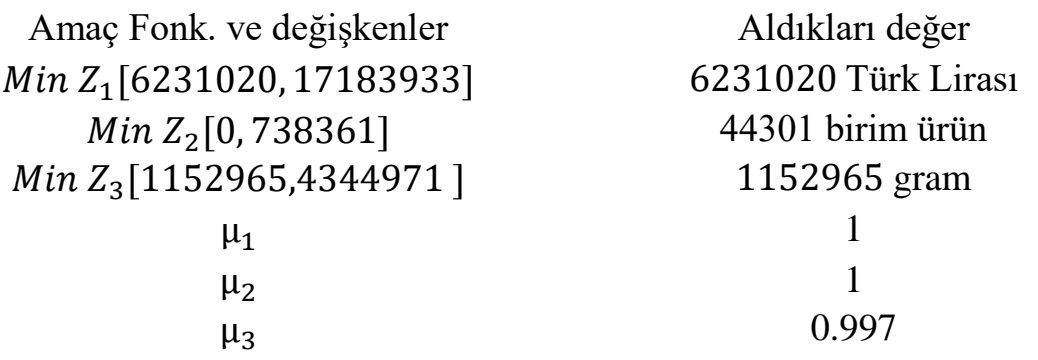

Bu metotla birlikte, $Z_{1}$ ve $Z_{2}$, kendi minimum değerlerini almışlar, $Z_{3}$ ise minimum değerine yakın bir değer almıştır. Şirket, planlama ufku boyunca, perakendecilerde 0 sayıda ardısmarlanmış ürün/veya stok fazlası ürün bulundurmuş, bir yandan da optimal bir şekilde toplam maliyetini ve toplam karbon salınımını da minimize edebilmiştir.

Sadece maliyet minimizasyonu gözetildiğinde, yani $Z_{1}$ 'in en küçüklendiği optimizasyon modelinde, depolarda tutulan envanter miktarı, tüm dönem boyunca 0 olurken, perakendecilerde tutulan toplam talep fazlası ürün sayısı 74440, ardısmarlanmış toplam miktar ise 73238 olmuştur. Sadece karbon minimizasyonu gözetildiğinde, yani $Z_{3}$ 'in en küçüklendiği optimizasyon modelinde ise depolarda tutulan envanter miktarı, tüm dönem boyunca 0 olurken, perakendecilerde tutulan toplam talep fazlası ürün ise 8722 olmuştur, ardısmarlanan ürün sayısı ise 0 'dır. Sadece $Z_{2}$ 'in en küçüklendiği optimizasyon modelinde ise depolarda tutulan envanter miktarı, tüm dönem boyunca 45875 olurken, perakendecilerde tutulan toplam talep fazlas 1 ürün ve ardısmarlanan ürün sayısı ise 0 olarak hesaplanmıştır. Ancak, bulanık ağırlıklı edinim metodu kullanılarak, 3 amacin aynı anda optimizasyon modelinde kullanılması durumunda ise, depolarda tutulan envanter miktarı, tüm dönem boyunca 0 olurken, perakendecilerde tutulan toplam talep fazlası ürün ve ardısmarlanan ürün sayısı da aynı şekilde 0 olarak bulunmuştur. Bu durum göstermektedir ki, her bir amacın aynı anda optimize edildiği optimizasyon metodları, her bir amaç için tatmin edici sonuçlar da vermektedir.

\section{SONUÇ}

Pratik açıdan bakıldığında, işletmeler ekonomik, çevresel veya operasyonel hedefler gibi değişken ve çoğu zaman çatışan hedefler altında çalışırlar. Bu zorlu kararla yüzleşen yöneticiler, amaçların aynı anda en iyileştirilebildiği yöntemleri uygulamak istemektedirler. Bu yöntem, toplam operasyonel maliyetlerinin ve ardısmarlanmış ve talep fazlası ürünlerin sayılarının da minimize edildiği, aynı zamanda da karbon salınımı konusunda yasal mevzuatlara uymaya istekli olan yöneticiler için harika bir araç sunmaktadır. Bu bulanık edinim yöntemi, yöneticilerin her bir hedef işlev için göreli önemlerini belirlermesine imkan sağlaması da ayrıca önemlidir, çünkü bu sayede yöneticiler, hedeflerin de birbirlerine göre önem derecelerini kendi tedarik zincirlerine göre belirleyebilirler. 
Bu çalışmada, üç farklı amacı aynı anda optimize etmeyi hedefleyen bir tedarik zinciri ağı tasarlanmış ve bunun için de karma tamsayılı doğrusal programlama modeli geliştirilmiştir. Amaç fonksiyonları olarak: (1) toplam dağıtım ve üretim maliyeti, (2) depolarda ve perakendecilerde ürünlerin depolanması ve elleçlenmesiyle ilişkili toplam karbon emisyonu, (3) perakendecilerden ardısmarlanmış veya talep fazlası ürünlerin sayısı olarak belirlenmiş̧ir. Geliştirilen model, hangi üreticiden, depolara ve oradan perakendecilere, perakendecilerin talebine cevap vermek için ne kadar miktarlarda taşınacağını, hangi fabrika ve depoların hangi boyutlarda açılacağını, depolardaki envanter miktarlarını da belirlemektedir. Bu çok amaçlı tam zamanında dağıtım modellemesi içeren yeşil bir tedarik zinciri modelinin çözümü için Tiwari ve diğ. (1987) tarafından geliştirilen bulanık ağırlıklandırma yaklaşımı, ilk defa kulanılmıştır. Bu bağlamda, bu çalışma, bulanık ağırlıklı edinim yöntemi kullanarak ekonomik, çevresel ve TZD bağlantılı erken/geç teslim edilen ürün sayısını azaltmak gibi farklı ve çelişen amaçları aynı anda iyileştirmek isteyen yöneticiler için bir örnek oluşturmaktır. Gelecekte, çok amaçlı tedarik zinciri problemleri için farklı çözüm yöntemleri geliştirilebilir ve etkinlikleri birbirleriyle karşılaştırılabilir. Ayrıca, bu modellerde maliyet ve/veya talep belirsizliği düşünülebilir ve belirsizlik içeren yeni çözüm metodolojileri bulanık modeller yoluyla geliştirilebilir. 


\section{KAYNAKÇA}

Amid, A., Ghodsypour, S. H., \& O’Brien, C. (2009). A weighted additive fuzzy multiobjective model for the supplier selection problem under price breaks in a supply Chain. International Journal of Production Economics, 121(2), 323-332. doi:http://dx.doi.org/10.1016/j.ijpe.2007.02.040

Arikan, F. (2013). A fuzzy solution approach for multi objective supplier selection. Expert Systems with Applications, 40(3), 947-952. doi:10.1016/j.eswa.2012.05.051

Banasik, A., Kanellopoulos, A., Claassen, G. D. H., Bloemhof-Ruwaard, J. M., \& van der Vorst, J. G. A. J. (2017). Closing loops in agricultural supply chains using multi-objective optimization: A case study of an industrial mushroom supply chain. International Journal of Production Economics, 183, 409-420. doi:https://doi.org/10.1016/j.ijpe.2016.08.012

Chan, F. T. S., Jha, A., \& Tiwari, M. K. (2016). Bi-objective optimization of three echelon supply chain involving truck selection and loading using NSGA-II with heuristics algorithm. Applied Soft Computing, 38, 978-987. doi:10.1016/j.asoc.2015.10.067

Fahimnia, B., Sarkis, J., \& Eshragh, A. (2015). A tradeoff model for green supply chain planning:A leanness-versusgreenness analysis. Omega, 54, 173-190. doi:10.1016/j.omega.2015.01.014

Farahani, R. Z., \& Elahipanah, M. (2008). A genetic algorithm to optimize the total cost and service level for just-in-time distribution in a supply chain. International Journal of Production Economics, 111(2), 229-243. doi:10.1016/j.ijpe.2006.11.028

Ghasimi, S. A., Ramli, R., \& Saibani, N. (2014). A genetic algorithm for optimizing defective goods supply chain costs using JIT logistics and each-cycle lengths. Applied Mathematical Modelling, 38(4), 1534-1547. doi:10.1016/j.apm.2013.08.023

Kavitha, C. a. V., C. (2013). Multi Objective Fuzzy Linear Programming Technique for Weighted Additive Model for Supplier Selection in Supply Chain Management. International Journal of Applied Mathematics and Informatics.

Mehlawat, M. K., \& Kumar, S. (2017). A multiobjective optimization model for optimal supplier selection in multiple sourcing environment. 2017, 26, 18.

Pan, W., Wang, F., Guo, Y., \& Liu, S. (2015). A Fuzzy Multiobjective Model for Supplier Selection under Considering Stochastic Demand in a Supply Chain. Mathematical Problems in Engineering, 2015, 8. doi:10.1155/2015/174585

Saaty, T. L. (2008). Decision making with the analytic hierarchy process. International Journal of Services Sciences, 1(1), 83-98. doi:10.1504/IJSSci.2008.01759

Sadeghi Rad, R., \& Nahavandi, N. (2018). A novel multi-objective optimization model for integrated problem of green closed loop supply chain network design and quantity discount. Journal of Cleaner Production, 196, 1549-1565. doi:https://doi.org/10.1016/j.jclepro.2018.06.034

Seifbarghy, M., Pourebrahim Gilkalayeh, A., \& Alidoost, M. (2011). A Comprehensive Fuzzy Multiobjective Supplier Selection Model under Price Brakes and Using Interval Comparison Matrices. Journal of Industrial and Systems Engineering, 4(4), 224-244.

Shaw, K., Shankar, R., Yadav, S. S., \& Thakur, L. S. (2012). Supplier selection using fuzzy AHP and fuzzy multiobjective linear programming for developing low carbon supply chain. Expert systems with applications, 39(9), 8182-8192.

Soleimani, H., Govindan, K., Saghafi, H., \& Jafari, H. (2017). Fuzzy multi-objective sustainable and green closed-loop supply chain network design. Computers \& Industrial Engineering, 109, 191-203. doi:https://doi.org/10.1016/j.cie.2017.04.038

Talaei, M., Farhang Moghaddam, B., Pishvaee, M. S., Bozorgi-Amiri, A., \& Gholamnejad, S. (2016). A robust fuzzy optimization model for carbon-efficient closed-loop supply chain network design problem: a numerical illustration in electronics industry. Journal of Cleaner Production, 113, 662-673. doi:10.1016/j.jclepro.2015.10.074

Tiwari, R. N., Dharmar, S., \& Rao, J. R. (1987). Fuzzy goal programming - An additive model. Fuzzy Sets and Systems, 24(1), 27-34. doi:https://doi.org/10.1016/0165-0114(87)90111-4

Wang, S., \& Sarker, B. R. (2006). Optimal models for a multi-stage supply chain system controlled by kanban under justin-time philosophy. European Journal of Operational Research, 172(1), 179-200. doi:10.1016/j.ejor.2004.10.001

Wang, W., Fung, R. Y. K., \& Chai, Y. (2004). Approach of just-in-time distribution requirements planning for supply chain management. International Journal of Production Economics, 91(2), 101-107. doi:10.1016/s09255273(03)00212-3

Zimmer, K. (2002). Supply chain coordination with uncertain just-in-time delivery. International Journal of Production Economics, 77(1), 1-15. doi:https://doi.org/10.1016/S0925-5273(01)00207-9

Zimmermann, H.-J. (1978). Fuzzy programming and linear programming with several objective functions. Fuzzy Sets and Systems, 1(1), 45-55. 